\title{
Population Genetic Structure of Puccinia striiformis in Northwestern China
}

Qiong Wan, Junmin Liang, Yong Luo, and Zhanhong Ma, Department of Plant Pathology, China Agricultural University, Beijing 100193, P. R. China

\begin{abstract}
Wan, Q., Liang, J.-M, Luo, Y., and Ma, Z.-H. 2015. Population genetic structure of Puccinia striiformis in northwestern China. Plant Dis. 99:1764-1774.

Wheat stripe rust, caused by Puccinia striiformis f. sp. tritici, is one of the most important fungal diseases of wheat in China. Xinjiang, Qinghai, and Gansu Provinces, located in the northwest of China, are the key regions for interregional epidemics of wheat stripe rust due to their geographic as well as crop-planting features, in relation to pathogen's life cycle, reproduction, and population genetics. To study the population genetic structures of the pathogen in these areas, 217 isolates of $P$. striiformis f. sp. tritici were collected from different geographic locations at various elevations in the three provinces. The amplified fragment length polymorphism (AFLP) genotypes and virulence phenotypes were analyzed for Xinjiang, Qinghai, and Gansu populations. Frequent genotypic exchanges between Xinjiang and Qinghai and between Qinghai and Gansu populations were detected, demonstrating

that the populations of Xinjiang and Gansu may not be completely isolated. Genotypic diversity in Gansu Province was much higher than that in Xinjiang or Qinghai Province. The Xinjiang population was genetically closer to the Qinghai population than to the Gansu population. The race dynamic patterns in Qinghai were consistent with those in Gansu but the similar component pattern of the race dynamics in Xinjiang appeared late, following those in Gansu and other interior epidemic regions of China. No significant correlation between the AFLP genetic distance and the virulence distance in the Xinjiang, Qinghai, and Gansu populations was determined. A possible recombination signature of the pathogen population was detected in Gansu population and some subpopulations in Qinghai but not in Xinjiang population.
\end{abstract}

Wheat stripe rust, caused by Puccinia striiformis f. sp. tritici, is one of the most important fungal diseases of wheat in many regions of the world (Chen 2005; Stubbs 1985; Wan et al. 2007). In China, severe stripe rust epidemics occurred in 1950, 1964, 1990, and 2002, causing yield losses up to 6.0, 3.2, 1.8, and 1.3 million metric tons, corresponding $29.3,13.3,1.8$ and $1.5 \%$ of the national wheat production, respectively ( $\mathrm{Li}$ and Zeng 2002; Wan et al. 2004; Wan et al. 2007).

Wheat stripe rust in China demonstrated unique features in interregional epidemics, expressing mainly as long-distance dispersal of the pathogen over geographic regions (Zeng and Luo 2006). The northwestern region of China, including Xinjiang, Qinghai, and Gansu, are the key regions for interregional epidemics because of their provision of oversummering and overwintering inoculum, climatic conditions, wheat growing seasons, and cultural practices. Almost all races of $P$. striiformis in China were first detected in Gansu (Li and Zeng 2002). A high genetic diversity of $P$. striiformis f. sp. tritici populations was revealed in Gansu Province (Duan et al. 2010; Mboup et al. 2009), where the pathogen can complete its life cycle at various elevations in the mountainous areas on wheat $(\mathrm{Li}$ and Zeng 2002; Zeng and Luo 2006), and alternative hosts for potential sexual reproduction have been reported (Zhao et al. 2013). Occurrence of possible recombination in $P$. striiformis f. sp. tritici populations in Gansu Province was inferred (Duan et al. 2010; Liu et al. 2011; Lu et al. 2011).

The average elevation in Qinghai Province is more than 3,000 m above sea level (a.s.l.) on a high plateau. Winter and spring wheat

Current address of Q. Wan: College of Plant Protection, Anhui Agricultural University, Hefei, Anhui 230036, P. R. China.

Current address of Y. Luo: Kearney Agricultural Center, University of California, Parlier, CA 93648

Corresponding authors: Y. Luo; E-mail: ygluo@ucanr.edu; and Z. Ma; E-mail:mazh@cau.edu.cn

Accepted for publication 3 June 2015.

http://dx.doi.org/10.1094/PDIS-02-15-0144-RE

(C) 2015 The American Phytopathological Society in Qinghai Province are both planted in the eastern regions, with elevations of 1,691 to 3,050 $\mathrm{m}$ a.s.l. The usual epidemic area of stripe rust in Qinghai was approximately 100,000 ha, and annual average yield loss was as high as 250,000 metric tons (Zhang 2008). Winter wheat is planted in September to October and harvested in July of the next year. Spring wheat is planted in March to April and harvested in August to September. During mid-May to late November, wheat stripe rust can be observed in Qinghai Province, and the disease first appears in mid-May on winter wheat planted at elevations of 1,691 to 2,024 m a.s.l. in Xunhua, Minhe, and Guide Counties, neighboring with Gansu Province (Zhang 2008). The eastern part of the province was considered to be the major oversummering area of $P$. striiformis f. sp. tritici in the province. However, winter in Qinghai is so cold that the fungus cannot survive ( $\mathrm{Li}$ et al. 1997). In other words, the spring epidemics in Qinghai may rely on the inoculum coming from other regions. Lu et al. (2011) stated that the stripe rust inoculum in Qinghai can come from both Longnan and Linxia but mainly from Longnan in Gausu, directly in the spring.

Xinjiang Province, located in central Eurasia, northwest of China, is the largest province of China, covering $1,664,900 \mathrm{~km}^{2}$. The geographic features in Xinjiang are unique compared with other regions. The wheat production areas in Xinjiang are geographically isolated, separated at a long distance from other wheat-growing areas of China by deserts and mountains. The border line of China in Xinjiang is 5,600 km long, neighboring eight countries: Russia, Kazakhstan, Kyrgyzstan, Tajikistan, Pakistan, Mongolia, India. and Afghanistan. Xinjiang is one of the major wheat-producing areas in China. The wheat-growing area in Xinjiang ranges from 600,000 to 750,000 ha, and the annual yield is about 375,000 metric tons ( $\mathrm{Li}$ et al. 2010). The pathogen was considered to be able to oversummer in the areas at high elevation in Xinjiang such as Zhaosu, Xinyuan and Aksu, where late-maturing winter or spring wheat is planted and volunteer plants existed (Li and Zeng 2002) that may serve as a bridging host of the pathogen to infect autumn plants of wheat. The pathogen may disperse outward but, most likely, just within Xinjiang (Li and Zeng 2002). The pathogen can overwinter only on snowcovered plants ( $\mathrm{Li}$ et al. 2010) that may cause infection in spring. Thus, the pathogen could complete its lifecycle in interior Xinjiang and serve as the initial inoculum of epidemics. The components and dynamics of $P$. striiformis $\mathrm{f}$. sp. tritici races in Xinjiang Province were found to be different from and likely behind the 
development of those in other interior regions of China (Li et al. 2010; Wu 1991). It is hypothesized that the occurrence and pattern of stripe rust epidemics in Xinjiang are different from those in other epidemic regions (Li and Zeng 2002). Thus, the P. striiformis $\mathrm{f}$. sp. tritici population structure might also be different from those in other epidemic regions. However, the features of population genetic structure of Xinjiang are still unclear.

The populations of $P$. striiformis $\mathrm{f}$. sp. tritici in these three provinces play an important role in stripe rust epidemics not only within these areas but also at an interregional level. Although it is clear that Gansu serves as an important source region, providing oversummering inoculum for interregional epidemics (Zeng and Luo 2006), there is still a question about whether the spores can disperse to the other two regions or whether there is an exchange in populations between any two of the three regions in the northwest of the country. On the other hand, where the inoculum in Qinghai and Xinjiang may come from is still unclear. Answering these questions may help obtain clues to determine whether the main inoculum of epidemics in these two regions could be endogenous or exogenous.

In order to answer the above questions, it is important to reveal the genetic population structures of the pathogen in northwestern regions of China. Such information is useful to understand the interregional epidemic patterns in northwestern China and how the three epidemic regions in northwestern China could relate to each other. In this study, isolates of $P$. striiformis $\mathrm{f}$. sp. tritici from different geographic locations with various elevations in Xinjiang, Qinghai, and Gansu Provinces were collected. The objectives of this study were to (i) analyze the genetic structure of the Xinjiang, Qinghai, and Gansu populations by using amplified fragment length polymorphism (AFLP) genotypes and virulence phenotypes; (ii) reveal the possible relationship in population genetics among Xinjiang, Qinghai, and Gansu populations; and (iii) infer the possible reproductive mode of the three populations.

\section{Materials and Methods}

$\boldsymbol{P}$. striiformis f. sp. tritici isolates. During the stripe rust epidemic period from mid-May to mid-July 2011, 81 P. striiformis $\mathrm{f}$. sp. tritici isolates were collected from 19 geographic locations of six counties of Xinjiang Province. An additional 106 P. striiformis f. sp. tritici isolates were collected from 17 geographic locations of six counties of Qinghai Province from October to December 2010 and November 2011 (Table 1; Fig. 1). These locations covered major stripe rust

Table 1. Puccinia striiformis f. sp. tritici isolates collected in Xinjiang, Qinghai, and Gansu provinces, northwestern China, used in this study

\begin{tabular}{|c|c|c|c|c|c|c|c|}
\hline Province: population code & $N^{\mathrm{a}}$ & County & Location $(n)^{\mathbf{b}}$ & Isolates for analysis ${ }^{\mathbf{c}}$ & Latitude, longitude & Cultivar & Elevation (m) \\
\hline \multirow[t]{5}{*}{ Xinjiang: ALT } & 37 & Aletai & Hongdun (13) & 4 & $47^{\circ} 46^{\prime} \mathrm{N}, 88^{\circ} 10^{\prime} \mathrm{E}$ & Bachun no. 6 & 776 \\
\hline & $\ldots$ & $\ldots$ & Liangfanchang (2) & - & $47^{\circ} 48^{\prime} \mathrm{N}, 88^{\circ} 01^{\prime} \mathrm{E}$ & $2002-77$ & 793 \\
\hline & $\ldots$ & $\ldots$ & Aweitan (14) & 3 & $47^{\circ} 45^{\prime} \mathrm{N}, 88^{\circ} 02^{\prime} \mathrm{E}$ & Xinchun no. 11 & 732 \\
\hline & $\ldots$ & $\ldots$ & Qiemuerqieke (3) & 1 & $47^{\circ} 48^{\prime} \mathrm{N}, 87^{\circ} 57^{\prime} \mathrm{E}$ & Xinchun no. 8 & 768 \\
\hline & $\ldots$ & $\ldots$ & Qiemuerqieke (5) & 3 & $47^{\circ} 48^{\prime} \mathrm{N}, 87^{\circ} 55^{\prime} \mathrm{E}$ & Xinchun no. 11 & 773 \\
\hline \multirow[t]{4}{*}{ QHE } & 24 & Qinghe & Arele (9) & 4 & $46^{\circ} 44^{\prime} \mathrm{N}, 90^{\circ} 19^{\prime} \mathrm{E}$ & Xinchun no. 17 & 1296 \\
\hline & $\ldots$ & $\ldots$ & Arele (5) & 4 & $46^{\circ} 44^{\prime} \mathrm{N}, 90^{\circ} 19^{\prime} \mathrm{E}$ & Xinchun no. 29 & 1297 \\
\hline & $\ldots$ & $\ldots$ & Arele (2) & 2 & $46^{\circ} 44^{\prime} \mathrm{N}, 90^{\circ} 28^{\prime} \mathrm{E}$ & Xinchun no. 23 & 1242 \\
\hline & $\ldots$ & $\ldots$ & Arele (8) & 5 & $46^{\circ} 44^{\prime} \mathrm{N}, 90^{\circ} 28^{\prime} \mathrm{E}$ & Xinchun no. 29 & 1251 \\
\hline \multirow[t]{9}{*}{$\mathrm{TC}$} & 18 & Tacheng & Ergong (2) & 2 & $46^{\circ} 48^{\prime} \mathrm{N}, 83^{\circ} 01^{\prime} \mathrm{E}$ & Xindong no. 18 & 609 \\
\hline & $\ldots$ & $\ldots$ & Kalahabake (1) & 1 & $46^{\circ} 46^{\prime} \mathrm{N}, 83^{\circ} 10^{\prime} \mathrm{E}$ & Xindong no. 33 & 650 \\
\hline & $\ldots$ & Emin & Baliying (1) & 1 & $46^{\circ} 36^{\prime} \mathrm{N}, 83^{\circ} 37^{\prime} \mathrm{E}$ & Xindong no. 18 & 559 \\
\hline & $\ldots$ & $\ldots$ & Shanghu (2) & 2 & $46^{\circ} 38^{\prime} \mathrm{N}, 83^{\circ} 47^{\prime} \mathrm{E}$ & Xindong no. 18 & 605 \\
\hline & $\ldots$ & $\ldots$ & Emaleguoleng (1) & 1 & $46^{\circ} 40^{\prime} \mathrm{N}, 84^{\circ} 01^{\prime} \mathrm{E}$ & Xinchun no. 11 & 674 \\
\hline & $\ldots$ & Yumin & Halabula (6) & 5 & $46^{\circ} 11^{\prime} \mathrm{N}, 82^{\circ} 59^{\prime} \mathrm{E}$ & Xindong no. 18 & 743 \\
\hline & $\ldots$ & $\ldots$ & Halabula (1) & 1 & $46^{\circ} 11^{\prime} \mathrm{N}, 82^{\circ} 58^{\prime} \mathrm{E}$ & Xindong no. 18 & 738 \\
\hline & $\ldots$ & $\ldots$ & Halabula (3) & 2 & $46^{\circ} 11^{\prime} \mathrm{N}, 82^{\circ} 59^{\prime} \mathrm{E}$ & Xindong no. 18 & 759 \\
\hline & $\ldots$ & $\ldots$ & Jianggesi (1) & - & $46^{\circ} 11^{\prime} \mathrm{N}, 82^{\circ} 56^{\prime} \mathrm{E}$ & Xindong no. 18 & 719 \\
\hline$X Y$ & 2 & Xinyuan & Nalati (2) & 2 & $43^{\circ} 22^{\prime} \mathrm{N}, 83^{\circ} 58^{\prime} \mathrm{E}$ & Ningchun no. 17 & 1295 \\
\hline Qinghai:XN & 23 & Xining & Ershilipu (23) & - & $36^{\circ} 43^{\prime} \mathrm{N}, 101^{\circ} 45^{\prime} \mathrm{E}$ & Abo & 2314 \\
\hline \multirow[t]{8}{*}{$\mathrm{XM}$} & 45 & Xunhua & Ahetan (8) & - & $35^{\circ} 52^{\prime} \mathrm{N}, 102^{\circ} 22^{\prime} \mathrm{E}$ & Unknown & 1884 \\
\hline & $\ldots$ & $\ldots$ & Dingjiang no. 1 (1) & - & $35^{\circ} 52^{\prime} \mathrm{N}, 102^{\circ} 26^{\prime} \mathrm{E}$ & Unknown & 1896 \\
\hline & $\ldots$ & $\ldots$ & Wajiang (1) & - & $35^{\circ} 48^{\prime} \mathrm{N}, 102^{\circ} 33^{\prime} \mathrm{E}$ & Unknown & 1992 \\
\hline & $\ldots$ & $\ldots$ & Hongzhuang (11) & 6 & $35^{\circ} 50^{\prime} \mathrm{N}, 102^{\circ} 33^{\prime} \mathrm{E}$ & Unknown & 1905 \\
\hline & $\ldots$ & $\ldots$ & Shangen (12) & 7 & $35^{\circ} 46^{\prime} \mathrm{N}, 102^{\circ} 33^{\prime} \mathrm{E}$ & Unknown & 2044 \\
\hline & $\ldots$ & $\ldots$ & Dingjiang no. 2 (2) & 1 & $35^{\circ} 52^{\prime} \mathrm{N}, 102^{\circ} 26^{\prime} \mathrm{E}$ & Unknown & 1889 \\
\hline & $\ldots$ & $\ldots$ & Labian (6) & 3 & $35^{\circ} 45^{\prime} \mathrm{N}, 102^{\circ} 33^{\prime} \mathrm{E}$ & Unknown & 2120 \\
\hline & $\ldots$ & Minhe & Guangzhong (4) & - & $35^{\circ} 52^{\prime} \mathrm{N}, 102^{\circ} 48^{\prime} \mathrm{E}$ & Unknown & 1849 \\
\hline \multirow[t]{8}{*}{ GH } & 38 & Guide & Dashijia (2) & 1 & $36^{\circ} 02^{\prime} \mathrm{N}, 101^{\circ} 25^{\prime} \mathrm{E}$ & Unknown & 2220 \\
\hline & $\ldots$ & $\ldots$ & Jiangcangma (8) & 3 & $36^{\circ} 00^{\prime} \mathrm{N}, 101^{\circ} 24^{\prime} \mathrm{E}$ & Unknown & 2299 \\
\hline & $\ldots$ & Jianzha & Dongmen (5) & - & $36^{\circ} 04^{\prime} \mathrm{N}, 101^{\circ} 55^{\prime} \mathrm{E}$ & Unknown & 2068 \\
\hline & $\ldots$ & $\ldots$ & Simen (4) & - & $36^{\circ} 03^{\prime} \mathrm{N}, 101^{\circ} 55^{\prime} \mathrm{E}$ & Unknown & 2120 \\
\hline & $\ldots$ & Hualong & Xiaduoba no. 1 (5) & - & $36^{\circ} 03^{\prime} \mathrm{N}, 101^{\circ} 56^{\prime} \mathrm{E}$ & Unknown & 2078 \\
\hline & $\ldots$ & $\ldots$ & Xiaduoba no. 2 (5) & - & $36^{\circ} 04^{\prime} \mathrm{N}, 101^{\circ} 56^{\prime} \mathrm{E}$ & Unknown & 2046 \\
\hline & $\ldots$ & $\ldots$ & Sheren (8) & 3 & $36^{\circ} 02^{\prime} \mathrm{N}, 101^{\circ} 59^{\prime} \mathrm{E}$ & Unknown & 2049 \\
\hline & $\ldots$ & $\ldots$ & Xiaduoba no. 3 (1) & 1 & $36^{\circ} 04^{\prime} \mathrm{N}, 101^{\circ} 55^{\prime} \mathrm{E}$ & Unknown & 2046 \\
\hline \multirow[t]{6}{*}{ Gansu: GS } & 30 & Zhuanglang & Yanghe (5) & - & $35^{\circ} 20^{\prime} \mathrm{N}, 105^{\circ} 59^{\prime} \mathrm{E}$ & Lantian no. 20 & 1691 \\
\hline & $\ldots$ & $\ldots$ & Baibao (5) & - & $35^{\circ} 13^{\prime} \mathrm{N}, 105^{\circ} 58^{\prime} \mathrm{E}$ & Lantian no. 26 & 1837 \\
\hline & $\ldots$ & Qinzhou & Zhaojiao (5) & - & $34^{\circ} 24^{\prime} \mathrm{N}, 105^{\circ} 39^{\prime} \mathrm{E}$ & Unknown & 1428 \\
\hline & $\ldots$ & Maiji & Xinyang (5) & - & $34^{\circ} 42^{\prime} \mathrm{N}, 105^{\circ} 32^{\prime} \mathrm{E}$ & Unknown & 1240 \\
\hline & $\ldots$ & Kangle & Basong (7) & - & $35^{\circ} 19^{\prime} \mathrm{N}, 103^{\circ} 30^{\prime} \mathrm{E}$ & Unknown & 2236 \\
\hline & $\ldots$ & Jishishan & Guanjiachuan (3) & - & $35^{\circ} 45^{\prime} \mathrm{N}, 102^{\circ} 54^{\prime} \mathrm{E}$ & Unknown & 2200 \\
\hline
\end{tabular}

\footnotetext{
a Number of isolates.

${ }^{\mathrm{b}}$ Number in parenthesis = number of isolates for amplified fragment length polymorphism analysis.

c Number of isolates used for virulence analysis; - indicates no isolates tested for pathotype analysis.
} 
epidemic regions in Xinjiang and Qinghai Provinces. Diseased leaves were sampled from plants of different varieties in the field. More than 10 sampling sites in each geographic location were selected, and 20 to 50 diseased leaves were collected in each sampling site. Leaves showing sporulation were separately stored in paper bags at $4{ }^{\circ} \mathrm{C}$ in desiccators. Additionally, in November 2010 with the same sampling strategy described above, 30 isolates were also collected from five counties of Gansu Province, where $P$. striiformis f. sp. tritici could overwinter and oversummer, serving as an inoculum source initiating interregional stripe rust epidemics in China (Table 1; Fig. 1).

To study the virulence phenotype diversity of the Xinjiang and Qinghai populations, a subset of 43 isolates (Table 1) from the 81 isolates in the Xingjiang population and a subset of 25 isolates (Table 1) among the 106 isolates in the Qinghai population, representing county, location, cultivar, and elevation, were selected to determine the races (see below for details).

Each $P$. striiformis f. sp. tritici isolate was obtained from a single pustule based on the assumption that a pustule was caused by infection of a single urediniospore. For increasing urediniospores, 10-dayold seedlings of universally susceptible 'Mingxian 169' (Chen et al. 2009) grown in a pot were used. The spores from the single pustule on a sampled leaf were picked and rubbed in a drop of water on the leaf surface of Mingxian 169. The inoculated plants were incubated in dew chamber at $10^{\circ} \mathrm{C}$ for $24 \mathrm{~h}$ in darkness, and then in a phytotron at $16^{\circ} \mathrm{C}$ for $14 \mathrm{~h}$ in light and $13^{\circ} \mathrm{C}$ for $10 \mathrm{~h}$ in darkness per day. About 15 days after inoculation, urediniospores were harvested, and a part of them was used for inoculation again, as described above for spore reproduction. The procedure was repeated until approximately $15 \mathrm{mg}$ of spores was obtained to extract DNA.

DNA extraction. For each isolate, spores ( 5 to $10 \mathrm{mg}$ ) were placed in a 2-ml centrifuge tube containing $200 \mu \mathrm{l}$ of extraction buffer (every $100 \mu \mathrm{l}$ consisted of $2.5 \mathrm{mg}$ of D-Sorbitol, $1 \mathrm{mg}$ of N-lauryl acid, $0.8 \mathrm{mg}$ of cetyltrimethylammonium bromide, $4.7 \mathrm{mg}$ of $\mathrm{NaCl}, 0.8 \mathrm{mg}$ of EDTA, and $10 \mathrm{mg}$ of Tris-Cl, $\mathrm{pH} \mathrm{8.0).} \mathrm{The} \mathrm{tubes} \mathrm{were} \mathrm{shocked}$ with five glass beads ( $5 \mathrm{~mm}$ in diameter) in each tube, with Vortex-Genie 2 at 2,000 rpm for $5 \mathrm{~min}$, followed by DNA extraction as described by Enjalbert et al. (2002). The DNA concentration of each isolate was determined with a spectrophotometer (Thermo Scientific NanoDrop 2000).

AFLP analysis. The AFLP procedure was carried out as described previously (Justesen et al. 2002; Vos et al. 1995). In this study, Pst I and $M s e I$ were used to digest 50 to $100 \mathrm{ng}$ of genomic DNA for each sample. A preselective amplification was performed by using Pst $\mathrm{I} 0$ and MseI0 (Table 2) under the following conditions: 30 cycles of $94^{\circ} \mathrm{C}$ for $30 \mathrm{~s}, 56^{\circ} \mathrm{C}$ for $30 \mathrm{~s}$, and $72^{\circ} \mathrm{C}$ for $60 \mathrm{~s}$. A specific amplification was performed by using each of eight MseI/PstI primer combinations. The primer combinations were determined based on a preliminary primer screening to select the most informative and clearly repeatable ones. These eight primer combinations are listed in Table 2. The primer combinations presented two selective nucleotides and each of these was modified by FAM or HEX fluorescence at $5^{\prime}$ of the MseI primer (Table 2). The selective amplification was carried out in a volume of $20 \mu \mathrm{l}$ containing $5 \mu \mathrm{l}$ of preselective production, which was diluted 30 times with double-distilled (dd) $\mathrm{H}_{2} \mathrm{O}, 1 \mu \mathrm{l}$ of PstI primer (50 ng/ $\mathrm{ll}), 1 \mu \mathrm{l}$ of $M s e \mathrm{I}$ primer $(50 \mathrm{ng} / \mu \mathrm{l}), 2.0 \mu \mathrm{l}$ of $10 \times$ polymerase chain reaction (PCR) buffer $\left(\mathrm{Mg}^{2+}\right.$ included $), 1.6 \mu \mathrm{l}$

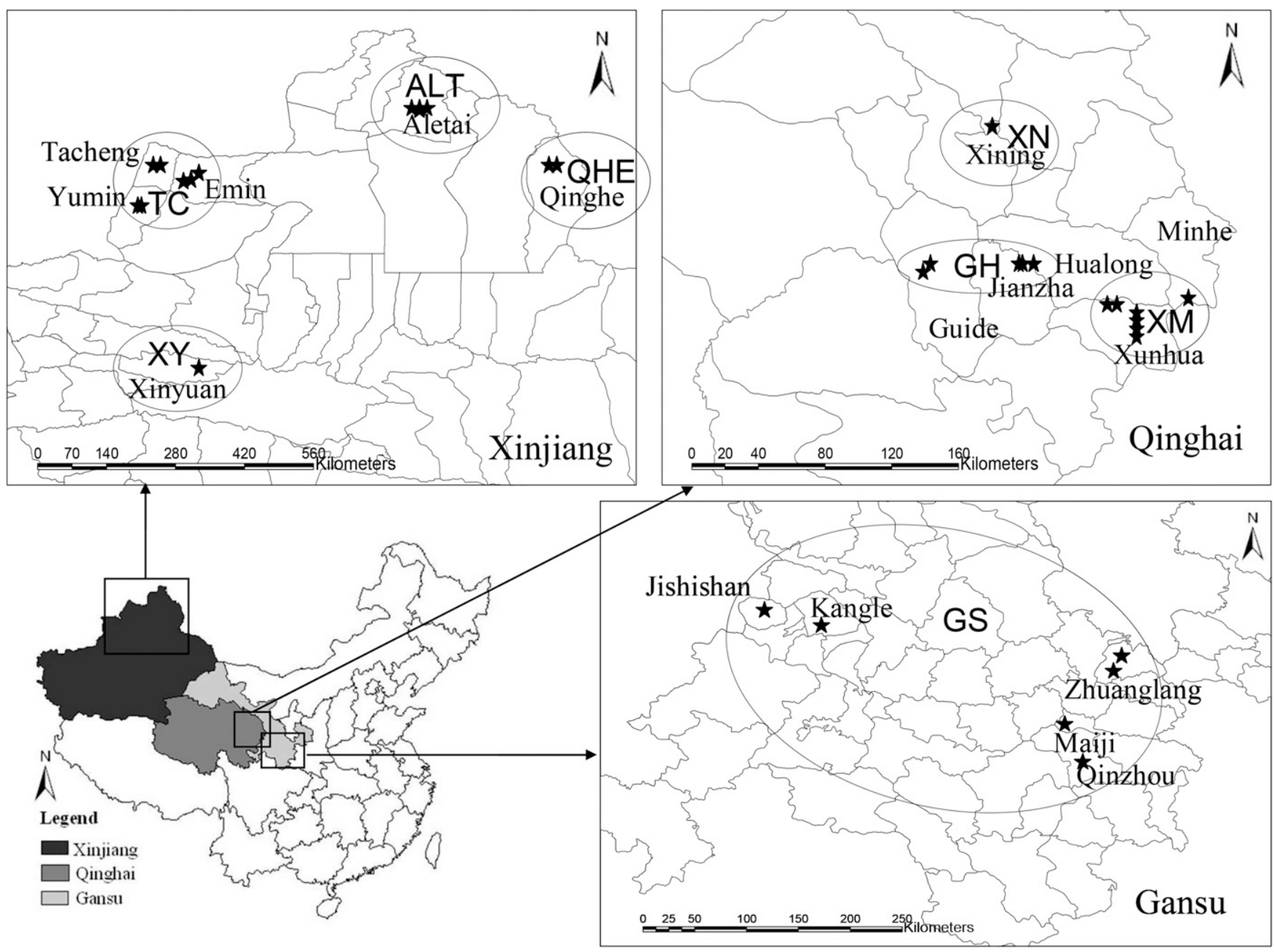

Fig. 1. Locations in Xinjiang, Qinghai, and Gansu Provinces of central China where 217 Puccinia striiformis f. sp. tritici isolates were collected. 
of dNTP ( $2.5 \mathrm{mmol} / \mathrm{liter}), 0.2 \mu \mathrm{l}$ of Taq polymerase $(5 \mathrm{U} / \mu \mathrm{l})$, and $9.2 \mu \mathrm{l}$ of $\mathrm{ddH}_{2} \mathrm{O}$. The amplification was performed under the following condition: 13 cycles of $94^{\circ} \mathrm{C}$ for $30 \mathrm{~s}$ and $65^{\circ} \mathrm{C}$ for $30 \mathrm{~s}$, with a $0.7^{\circ} \mathrm{C}$ decrement per cycle; $72^{\circ} \mathrm{C}$ for $60 \mathrm{~s}$; and then 25 cycles of $94^{\circ} \mathrm{C}$ for $30 \mathrm{~s}, 56^{\circ} \mathrm{C}$ for $30 \mathrm{~s}$, and $72^{\circ} \mathrm{C}$ for $60 \mathrm{~s}$. Final PCR products $(0.5 \mu \mathrm{l})$ were added to $0.5 \mu \mathrm{l}$ of size standard of 500-GS-Liz and $9.0 \mu \mathrm{l}$ of highly deionized-formamide, then heated for $5 \mathrm{~min}$ at $94^{\circ} \mathrm{C}$. The denatured sample was electrophoresed with the POP-7 polymer on ABI 3730XL automatic DNA analyzer (Applied Biosystems) at $15,000 \mathrm{~V}$ for $1 \mathrm{~h}$. The obtained electrophoretogram was viewed by using Genograper-2.1 software. Only polymorphic fragments showing high quality and strong intensity shared by at least two individuals in the range of 35 to $500 \mathrm{bp}$ were scored as binary characters (presence $=$ " 1 " and absence $=$ " 0 ") for each isolate. In order to confirm the consistency of the polymorphic pattern, a number of selected isolates were used to split into two subsamples and separately extract DNA for AFLP. The result showed that the AFLP fingerprints for the two duplications of each sample were consistent among readable bands.

Determination of races. Races of the studied isolates were determined by using a set of 19 differentials with a unique single resistance gene or combination of resistance genes (Chen et al. 2009; Wan et al. 2004). For each isolate, $5 \mathrm{mg}$ of fresh urediniospores suspended in $5 \mathrm{ml}$ of $0.05 \%$ Tween-20 was sprayed on five to seven seedling plants ( 10 days old) of each differential cultivar and on universally susceptible Mingxian 169 as a control. The inoculated plants were then incubated under the conditions previously described until they produced the spores needed. Eighteen days after inoculation, when Mingxian 169 showed typical stripe rust symptoms, the inoculated plants were assessed for disease severity individually by using a 0 -to-4 scale system (Chen et al. 2009). Host reactions rated 0 to 2 were defined as resistant and 3 to 4 as susceptible. The corresponding races of the tested isolates were determined by using the abbreviations of specific wheat differential genotypes or CYR numbering based on the chronological order of the appearance (Chen et al. 2009).

Data analysis. The AFLP genotypes and their corresponding frequencies in Xinjiang, Qinghai, and Gansu populations were determined by using the Multilocus 1.3 software program (Agapow and Burt 2001). The genotypic diversities of Xinjiang, Qinghai, and Gansu populations were analyzed, and the genotypes shared by any two and all of three of the populations were determined. A clone-corrected AFLP dataset with the genotypes presented only once was generated to avoid the effect of clonality. The clustering analysis on the AFLP genotypes obtained from this study was conducted by using the Neighbor program in the Phylip software package (Felsenstein 1989). The majority rule consensus tree, which consisted of all groups that occurred in more than $50 \%$ of the trees investigated, was selected using the Consense program and the result was visualized with the tool TreeView (Page 1996).

To assess gene diversity within and among the three populations, the number and the percentage of polymorphic loci, Nei's gene diversity and Shannon's information index were estimated by using POPGENE software, version 1.32 (Yeh et al. 1997).

In addition to the Gansu population (GS), in order to analyze the population structure within Xinjiang and Qinghai, the samples from Xinjiang had been grouped into three subpopulations based on geographic locations: ALT (Aletai included), QHE (Qinghe included), and TC (Tacheng, Emin, and Yumin included). The samples from Qinghai were also grouped into three subpopulations: XN (including Xining), XM (including Xunhua and Minhe), and GH (including Guide, Jiazha, and Hualong) (Fig. 1; Table 1). To evaluate population genetic differentiations within Xinjiang and Qinghai populations, those among Xinjiang, Qinghai, and Gansu populations, and those among the seven subpopulations (three from Xinjiang, three from Qinghai, and one from Gansu), the analysis of molecular variance (AMOVA; Excoffier et al. 1992) with 1,000 permutations was performed by using the software Genalex 6.2 (Peakall and Smouse 2006). The parameter $\varphi p t$ was used to determine the differentiation between any two subpopulations. If the observed $\varphi p t$ value differed significantly from zero, the null hypothesis of no genetic difference among the populations was rejected. The genetic difference among any two tested populations was considered significant when $\varphi p t>$ 0.25 . The software Genalex 6.2 was also used to perform the principal coordinate analysis (PCA) based on Nei's gene distances to plot the distribution of genotypes of Xinjiang, Qinghai, and Gansu populations.

To obtain the information on possible reproductive mode of the studied populations, the AFLP genotypes of Xinjiang, Qinghai, and Gansu populations were analyzed for linkage disequilibrium described by a standardized association index $\left(r_{d}\right.$; Smith et al. 1993). The $r_{d}$ distribution in randomized datasets was generated with 1,000 permutations using the Multilocus program (Agapow and Burt 2001). The hypothesis was that when the observed $r_{d}$ was located within the distribution of $r_{d}$ from permutation, the possible existence of recombination in the tested population can be inferred. The $P$ value was used to draw the conclusion.

On analysis of races, the numbers of isolates of each tested race in Xinjiang and Qinghai were obtained. The distribution of the corresponding races for each subpopulation was determined. The race frequencies of the 43 tested isolates in Xinjiang Province and 25 tested isolates in Qinghai Province were determined. For each isolate on a differential, " 0 " was assigned for the reaction types from 0 to 2 and " 1 " for the reaction types from 3 to 4 . Thus, a binary matrix was generated. NTSYS pc2.1 (Rohlf 2000) was used to calculate the similarity matrices of the AFLP genotypic and phenotypic data of the isolates from Xinjiang and Qinghai.

Table 2. Mse/Pst primer combinations and their polymorphic bands used for amplified fragment length polymorphism (AFLP) analysis on Puccinia striiformis isolates obtained from Xinjiang, Qinghai, and Gansu Provinces of China in this study

\begin{tabular}{lcccc}
\hline Primer combination & Sequence $\left(\mathbf{5}^{\prime} \mathbf{3}^{\prime}\right)^{\mathbf{a}}$ & Labeled fluorescence & $\begin{array}{c}\text { Number of } \\
\text { polymorphic bands }\end{array}$ & Band position (bp) \\
\hline M12/P14 & MseI0+AC/PstI0+AT & FAM & 14 & $460,382,363,338,315,310,273,254,234,219$, \\
& & FAM & $115,87,60,37$ \\
M15/P16 & MseI0+CA/PstI0+CC & FAM & 10 & $468,420,406,397,378,366,316,275,161,100$ \\
M26/P12 & MseI0+TT/PstI0+AC & FAM & 15 & $485,473,465,460,412,402,374,343,329,301$, \\
& MseI0+AC/PstI0+AA & HEX & 6 & $254,137,114,97,78$ \\
M12/P11 & MseI0+CC/PstI0+CC & HEX & 12 & $455,445,398,351,334,36$ \\
M16/P16 & MseI0+CC/PstI0+AC & HEX & 9 & $473,456,406,378,350,343,329,303,233,169$, \\
M16/P12 & MseI0+TG/PstI0+CA & HEX & 8 & $382,337,315,254,133,113,87,60,37$ \\
M25/P15 & MseI0+CG/PstI0+GT & & 14 & $474,420,409,399,351,246,101,35$ \\
M17/P22 & & & $480,440,420,406,402,386,343,320,302,297$, \\
& & & $275,245,161,51$
\end{tabular}

\footnotetext{
a $M s e \mathrm{I} 0+\mathrm{AC}$ corresponds to $M s e \mathrm{I0}$ primer (5'-GACGATGAGTCCTGAGTAA-3') plus two selective nucleotides (AC), and PstI0+AT to PstI0 primer (5'-GTA GACTGCGTACATGCAG-3') plus two selective nucleotides (AT).
} 
Then, a mantel analysis implemented in NTSYS pc2.1 was performed to determine the existence of the correlation between the AFLP and the virulence similarity matrices of the Xinjiang and Qinghai populations.

\section{Results}

Genotypic diversity. In total, 88 AFLP fragments were obtained (Table 2). The 217 isolates from the three provinces revealed 72 genotypes. In total, 37 AFLP genotypes were obtained from 81 isolates in Xinjiang (genotypic diversity $=0.46$ ), 42 AFLP genotypes from 106 isolates in Qinghai (genotypic diversity $=0.40$ ), and 26 AFLP genotypes from 30 isolates in Gansu (genotypic diversity $=0.87$ )
(Table 3), a genotypic diversity higher than those of Xinjiang or Qinghai.

In the Xinjiang and Gansu populations, seven genotypes (alt5, alt15, qhe5, qhe6, tc4, tc5, and xy1) were shared (Table 3; Fig. 2) as 18.92 and $26.92 \%$, respectively, of total genotypes in the populations. The frequencies of all seven genotypes in the Gansu population, except tc5, were higher than those in the Xinjiang population. Among the Qinghai and Gansu populations, 10 genotypes (alt5, qhe6, tc5, xy1, xn6, xn7, xm2, xm5, xm11, and xm12) were shared (Table 3; Fig. 2) as 23.81 and $38.46 \%$, respectively, of total genotypes in the populations. The frequencies of all the genotypes in the Gansu population, except xy1, were higher than those in the

Table 3. Information on amplified fragment length polymorphism (AFLP) genotypes obtained from the three provinces of northwestern China

\begin{tabular}{|c|c|c|c|c|}
\hline Province, population ${ }^{\mathbf{a}}$ & Number of isolates & Number of AFLP genotypes & Genotypic diversity & $\begin{array}{l}\text { AFLP genotypes (number of isolates for the } \\
\text { corresponding genotype) }^{\mathbf{b}}\end{array}$ \\
\hline \multicolumn{5}{|l|}{ Xinjiang } \\
\hline ALT & 37 & 25 & 0.68 & $\begin{array}{l}\text { alt1(2),alt2(1),alt3(1),alt4(2),alt5(1),alt6(1), } \\
\text { alt7(1), alt8(1),alt9(1),alt10(2),alt11(1), } \\
\text { alt12(1), alt13(1),alt14(1),alt15(1),qhe1(2), } \\
\text { qhe4(4), qhe6(1),qhe9(1),qhe10(2),tc2(5), } \\
\text { tc3(1),tc5(2), tc8(1),xy1(1) }\end{array}$ \\
\hline QHE & 24 & 14 & 0.58 & $\begin{array}{l}\text { qhe1(2),qhe2(2),qhe3(1),qhe4(1),qhe5(1), } \\
\text { qhe6(1), qhe7(2),qhe8(1),qhe9(1),qhe10(1), } \\
\text { tc1(2),tc2(6), tc5(2),tc6(1) }\end{array}$ \\
\hline $\mathrm{TC}$ & 18 & 11 & 0.61 & $\begin{array}{l}\operatorname{tc} 1(2), \operatorname{tc} 2(2), \operatorname{tc} 3(1), \operatorname{tc} 4(1), \operatorname{tc} 5(2), \operatorname{tc} 6(1), \\
\text { tc7(1), tc8(2),tc9(2),tc10(2),xy2(2) }\end{array}$ \\
\hline $\mathrm{XY}$ & 2 & 2 & 1.00 & xy1(1),xy2(1) \\
\hline Entire population & 81 & 37 & 0.46 & \\
\hline \multicolumn{5}{|l|}{ Qinghai } \\
\hline $\mathrm{XN}$ & 23 & 17 & 0.74 & $\begin{array}{l}\text { xn1(1),xn2(1),xn3(1),xn4(1),xn5(1),xn6(1), } \\
\text { xn7(1),alt5(2),alt6(1),qhe4(2),qhe6(2), } \\
\text { qhe8(1), tc1(2),tc2(2),tc3(1),tc7(2),tc8(1) }\end{array}$ \\
\hline $\mathrm{XM}$ & 45 & 27 & 0.60 & $\begin{array}{l}\text { xm1(1),xm2(1),xm3(1),xm4(1),xm5(1), } \\
\text { xm6(1), xm7(1),xm8(1),xm9(1),xm10(1), } \\
\text { xm11(1), xm12(1),alt2(1),alt5(5),alt6(2), } \\
\text { alt8(1),qhe4(1), tc1(5),tc2(5),tc5(1),tc6(1), } \\
\text { tc8(3),tc9(1),xy1(4), xy2(1),xn2(1),xn6(1) }\end{array}$ \\
\hline GH & 38 & 18 & 0.47 & $\begin{array}{l}\text { gh1(1),gh2(1),gh3(1), alt2(1), alt5(4), alt6(2), } \\
\text { alt9(1),alt10(1),qhe4(5),qhe7(1),tc1(2),tc2(7), } \\
\text { tc5(2),tc8(3),xy1(1),xy2(2),xn2(2),xn5(1) }\end{array}$ \\
\hline Entire population & 106 & 42 & 0.40 & $\ldots$ \\
\hline \multicolumn{5}{|l|}{ Gansu } \\
\hline GS & 30 & 26 & 0.87 & $\begin{array}{l}\text { gs1(1),gs2(1),gs3(1),gs4(1),gs5(1),gs6(1), } \\
\text { gs7(1), gs8(1),gs9(1),gs10(1),gs11(1), } \\
\text { gs12(1),gs13(1), alt5(1),alt15(2),qhe5(1), } \\
\text { qhe6(1),tc4(1),tc5(2), xy1(1),xn6(2),xn7(1), } \\
\text { xm2(1),xm5(2),xm11(1), xm12(1) }\end{array}$ \\
\hline
\end{tabular}

a ALT = Aletai included, QHE = Qinghe included, TC = Tacheng, Emin, and Yumin included, XN = including Xining, XM = including Xunhua and Minhe, and $\mathrm{GH}=$ including Guide, Jiazha, and Hualong.

${ }^{b}$ The first two or three letters refer to the abbreviation of population.

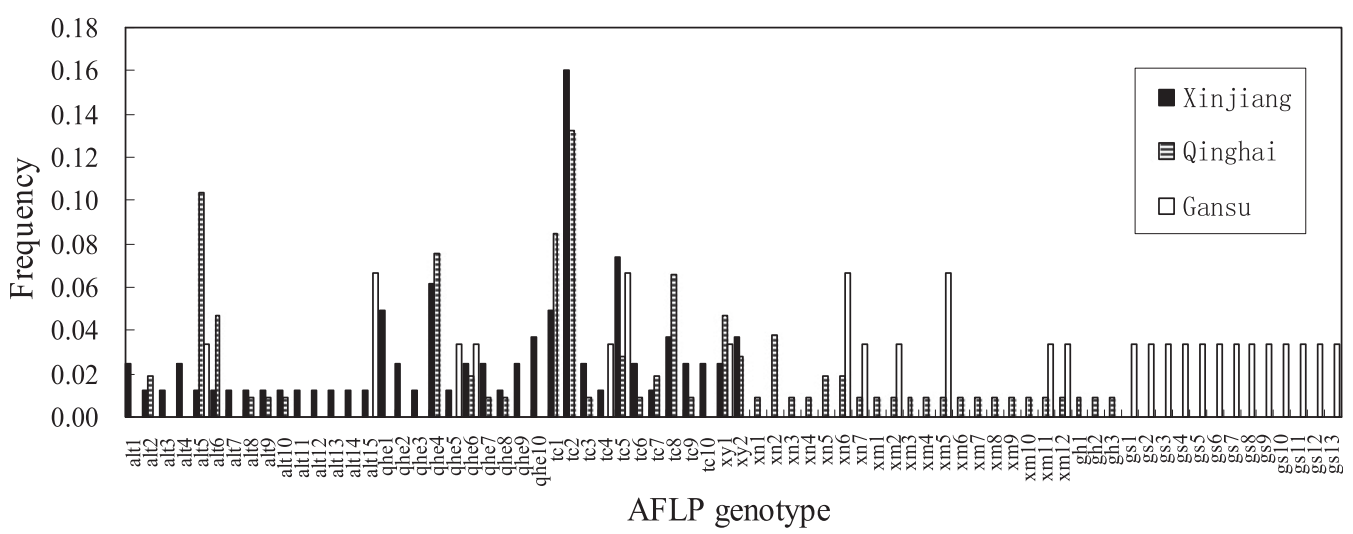

Fig. 2. Amplified fragment length polymorphism (AFLP) genotypes of Puccinia striiformis f. sp. tritici and frequency of the corresponding isolates in Xinjiang, Qinghai, and Gansu Provinces obtained in this study. 
Qinghai population. Among Xinjiang and Qinghai populations, 20 genotypes were shared (Table 3; Fig. 2) as 54.05 and $47.62 \%$, respectively, of total genotypes in the populations. The frequencies of 12 genotypes in Xinjiang population were higher than those in Qinghai population. Four genotypes (alt5, qhe6, tc5, and xy1) were shared in Xinjiang, Qinghai, and Gansu populations. Thus, the frequency of shared genotypes between Xinjiang and Qinghai was higher than those between Gansu and Xinjiang and between Gansu and Qinghai.

Among the 72 genotypes, 13 genotypes were only detected in Xinjiang (35.14\% of 37 genotypes in Xinjiang), 16 genotypes were only detected in Qinghai (38.10\% of 42 genotypes in Qinghai), and 13 genotypes were only detected in Gansu (50.00\% of 26 genotypes in Gansu). Thus, the frequency of the unique genotypes in Gansu was the highest among the three populations.

Six genotype groups were revealed from all the genotypes based on clustering analysis (Fig. 3), and these groups were distributed in different geographic locations. All six groups (A to F) were detected in all the three provinces. The frequencies of group $\mathrm{C}$ were 0.33 , 0.38, and 0.47 for Xinjiang, Qinghai, and Gansu, respectively, higher than other groups. The corresponding frequencies of groups A, C, and $\mathrm{E}$ in Gansu were higher than those in Xinjiang and Qinghai, while those of groups D and F were lower in Gansu than in Qinghai and Xinjiang. The result implied the existence of genetic exchange among Xinjiang, Qinghai, and Gansu populations.

Gene diversity. The percentages of polymorphic loci were as high as $98.86 \%$ in Xinjiang, $100.00 \%$ in Qinghai, and $100.00 \%$ in Gansu (Table 4). Compared with the result for the Gansu population, the Nei's gene diversity and Shannon's information index for the Xinjiang population were little higher, while those for the Qinghai population were much lower (Table 4). The orders of the gene diversities

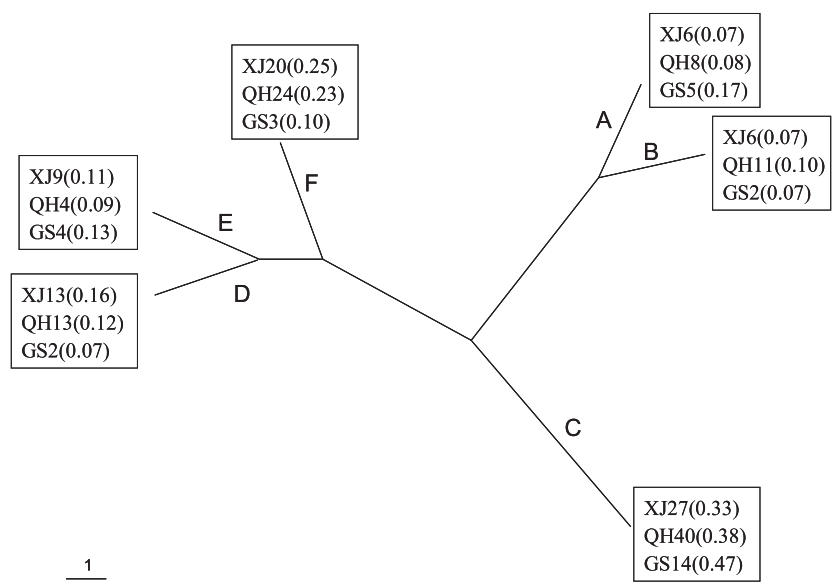

Fig. 3. Unrooted tree generated from amplified fragment length polymorphism (AFLP) data for Puccinia striiformis f. sp. Tritici based on 217 isolates collected from Xinjiang $(\mathrm{XJ})$, Qinghai (QH), and Gansu (GS) Provinces in this study. Isolates were classified into six genotype groups $(A, B, C, D, E$, and $F)$, each consisting of several from a total of 72 AFLP genotypes. Numbers after the two capital letters of the province abbreviation represent the numbers of corresponding isolates, and numbers within parentheses represent the frequencies of corresponding isolates. The length of the bar equals one polymorphism.

Table 4. Parameters of gene diversity in Xinjiang, Qinghai, and Gansu populations of Puccinia striiformis obtained in this study

\begin{tabular}{lcrcc}
\hline Population & $\mathbf{N P}^{\mathbf{a}}$ & $\mathbf{P}(\boldsymbol{\%})^{\mathbf{b}}$ & $\boldsymbol{h}^{\mathbf{c}}$ & $\mathbf{I}^{\mathbf{d}}$ \\
\hline Xinjiang & 87 & 98.86 & $0.47 \pm 0.06$ & $0.66 \pm 0.08$ \\
Qinghai & 88 & 100.00 & $0.34 \pm 0.11$ & $0.52 \pm 0.13$ \\
Gansu & 88 & 100.00 & $0.45 \pm 0.06$ & $0.64 \pm 0.07$
\end{tabular}

\footnotetext{
${ }^{a}$ Number of polymorphic loci.

${ }^{b}$ Percentage of polymorphic loci.

${ }^{c}$ Nei's gene diversity.

d Shannon's Information index.
}

of the seven subpopulations based on Nei's gene diversity and Shannon's information Index was GS $>$ XN $>$ ALT $>$ TC $>$ QHE $>$ $\mathrm{XM}>\mathrm{GH}$ (data not shown).

The result of AMOVA within the Xinjiang population demonstrated that the most variation $(99 \%)$ was from within populations, and only $1 \%$ variation was from among populations. Similarly, in the Qinghai and Gansu populations, the result of AMOVA demonstrated that the most variation $(98 \%)$ was from within populations, and only $2 \%$ variation was from among populations (Table 5). Based on the value of $\varphi p t$, the order of the genetic differentiations within populations was Gansu > Qinghai > Xinjiang. The genetic differentiation for Xinjiang versus Qinghai populations (0.019) was much lower than those for Xinjiang versus Gansu (0.050) and for Qinghai versus Gansu (0.072, Table 5). This was also confirmed by the PCA analysis (Fig. 4) that the isolates located in the same coordinate among the Xinjiang and Qinghai populations were more than those among the Xinjiang and Gansu populations and among the Qinghai and Gansu populations. Thus, the Xinjiang population was genetically closer to the Qinghai than to the Gansu population. Therefore, the Xinjiang and Qinghai populations can be reasonably considered as one big population, while the Gansu population could belong to another one based on the PCA result (Fig. 4).

The result of pairwise matrix of genetic variation $(\varphi p t)$ among the seven subpopulations (Table 6) showed that, although $\varphi p t$ values (Table 6, low left angle) among most pairs of two subpopulations were different, all of them did not reach the significant level at $\varphi p t<0.25$ (Table 6). Higher genetic differentiations were found between GS and ALT, GS and XN, GS and XM, and GS and GH, while much lower genetic differentiations were found between ALT and QHE, and $\mathrm{XM}$ and $\mathrm{GH}$.

Test for reproductive mode. The standardized association index $r_{d}$ of the observed dataset for the entire Xinjiang population was 0.0121 (Fig. 5A), located out of the distribution of $r_{d}$ from 1,000 randomized datasets $(0.000$ to 0.008$)$. Moreover, the $r_{d}$ of the observed dataset in each of the three subpopulations in Xinjiang showed that all of the observed $r_{d}$ values were located out of the corresponding distributions of $r_{d}$ from 1,000 randomized datasets (Figs. 5D and $4 \mathrm{E}$ and $\mathrm{F}$ ). Thus, at least the sampled Xinjiang subpopulations might be from clonal populations with very small chance of free recombination. The standardized association index $r_{d}$ of the observed dataset for the entire Qinghai population was 0.0127 (Fig. 5B) at $P<0.001$, located out of the distribution of $r_{d}$ from 1,000 randomized datasets (0.002 to 0.011). However, the $r_{d}$ of the observed dataset in the subpopulation XN in Qinghai showed that the observed $r_{d}$ value was located inside the corresponding distributions of $r_{d}$ from 1,000 randomized datasets (Fig. 5G) at $P=0.001$. Thus, the recombination signature may exist in this subpopulation in Qinghai. Moreover, the Gansu population showed that the $r_{d}$ of the observed dataset was

Table 5. Results of analysis of molecular variance (AMOVA) for Puccinia striiformis subpopulations sampled from Xinjiang, Qinghai, and Gansu Provinces of China in this study using the amplified fragment length polymorphism data for each population

\begin{tabular}{|c|c|c|c|c|}
\hline \multirow[b]{2}{*}{ Population } & \multicolumn{2}{|c|}{ Genetic variation (\%) } & \multirow[b]{2}{*}{$\Phi p t^{\mathbf{a}}$} & \multirow[b]{2}{*}{$P^{\mathbf{b}}$} \\
\hline & $\begin{array}{c}\text { Among } \\
\text { populations }\end{array}$ & $\begin{array}{c}\text { Within } \\
\text { population }\end{array}$ & & \\
\hline Xinjiang & 1 & 99 & 0.013 & 0.016 \\
\hline Qinghai & 2 & 98 & 0.018 & 0.001 \\
\hline Gansu & 2 & 98 & 0.024 & 0.021 \\
\hline $\begin{array}{l}\text { Xinjiang versus } \\
\text { Qinghai }\end{array}$ & 2 & 98 & 0.019 & 0.001 \\
\hline $\begin{array}{l}\text { Xinjiang versus } \\
\text { Gansu }\end{array}$ & 5 & 95 & 0.050 & 0.001 \\
\hline Qinghai versus Gansu & 7 & 93 & 0.072 & 0.001 \\
\hline
\end{tabular}


0.0003 and located inside the distribution of $r_{d}$ from 1,000 randomized datasets $(0.000$ to 0.008$)$ (Fig. 5C). Thus this population could be from a recombined or mixed with clonal population at $P=0.764$.

Races in Xinjiang, Qinghai, and Gansu. From 43 isolates among the samples in the Xinjiang population, 17 races were identified (Table 7; Fig. 6). The frequency of race Su11-8 was 0.12, while that of each of the races CYR21, HY-9, Su11-3, and Su11-10 was 0.09. The remaining 12 races showed frequencies from 0.02 to 0.07 (Fig. 6).

Two races (Su11-3 and CYR21) were detected in both ALT and QHE, two races (Su11-3 and Su11-8) in both ALT and TC, and five races (HY-9, Su11-3, Su11-4, Su11-10, and CYR17) in both QHE and TC. Moreover, race Su11-3 was shared by ALT, QHE, and TC (Table 7).

More than $90 \%$ of the tested isolates in Xinjiang Province were virulent to Fulhard $(\mathrm{Yr}+)$, Lutescens $128(\mathrm{Yr}+)$, Abbondanza $(\mathrm{Yr}+)$, and Early Premium $(\mathrm{Yr}+$ ) (Table 8). More than 50\% of the isolates were virulent to Trigo Eureka $(Y r 6)$, Mentana $(Y r+)$, Funo $(Y r \mathrm{~A}+)$, Danish 1 ( $Y r 3)$, Fengchan $3(Y r 1)$, and Shuiyuan $11(Y r \mathrm{Su})$ (Table 8). However, no isolates were virulent to Lovrin 13 (Yr9+), Zhong $4(Y r+)$, Triticum spelta album (Yr5), and Guinong $22(Y r+)$, and few isolates virulent to Lovrin $10(\mathrm{Yr} 9)$ or Hybrid 46 (Yr4b, H46) were found (Table 8).

From 25 isolates from the samples in the Qinghai population, 17 races were also identified (Table 7; Fig. 6). Among the 17 races, the race Su11-18 showed a frequency of 0.16 , and races Su11-4 and CYR33 each showed a frequency of 0.08 . The remaining 14 races showed a frequency of 0.04 (Fig. 6).

As a comparison, Table 7 lists the result from Huang et al. (2014) based on 320 P. striiformis $\mathrm{f}$. sp. tritici samples collected from Gansu Province in 2010, in which 30 races were identified (Table 7; Fig. 6). Among these races, CYR32 and CYR33 showed high frequencies of 0.20 and 0.19 , respectively, and race Su11-4 showed a frequency of 0.17 . The remaining 27 races showed frequencies of less than 0.10 (Fig. 6).

More than $90 \%$ of the tested isolates in Qinghai Province were virulent to Lutescens $128(Y r+)$, Abbondanza $(Y r+)$, Funo $(Y r A+)$, and Jubilejina 2 (Ju1, Ju2, Ju3, and Ju4) (Table 8). More than $50 \%$ of the isolates were virulent to Fulhard $(Y r+)$, Mentana $(Y r+)$, Early Premium $(Y r+)$, Danish $1(Y r 3)$, Fengchan $3(Y r 1)$, Shuiyuan $11(\mathrm{YrSu})$, and Lovrin $10(Y r 9)$ (Table 8). Thus, these $Y r$ genes should be avoided for use in local breeding for disease resistance in Qinghai. However, no isolates were virulent to $T$. spelta album $(Y r 5)$, and a few isolates were virulent to Zhong $4(\mathrm{Yr}+)$ or Guinong $22(\mathrm{Yr}+)$ (Table 8).
The observed Mantel correlation coefficient $(r)$ between the AFLP and the virulence similarity matrices in the Xinjiang population was $0.032(P=0.632)$, while that in Qinghai population was 0.037 $(P=0.659)$. Thus, the correlation between the AFLP and the virulence similarity matrices was not significant in both the Xinjiang and Qinghai populations.

\section{Discussion}

Exchanges in genotypes between Xinjiang and Qinghai and between Qinghai and Gansu populations were found. Because 19 and $27 \%$ of total genotypes were shared in Xinjiang and Gansu populations, respectively, these two populations may not be completely isolated. Furthermore, Xinjiang and Qinghai populations can be considered to be one population due to the high frequencies of shared AFLP genotypes among the two populations. This may reflect the possibility of the existence of spore dispersal through prevailing winds between these two regions; however, further studies are still needed to confirm the hypothesis. Moreover, a previous study found similar low frequencies of shared AFLP genotypes between Yunnan $(17 \%)$ and Gansu (32\%) populations. Thus, some extent of isolation between these two populations was indicated (Liu et al. 2011). However, high frequencies of shared genotypes were detected between Ningxia (46\%) and Gansu populations (72\%) (Liang et al. 2013), demonstrating the existence of frequent genotypic exchange between the two provincial populations. Furthermore, high genetic identity and the possibility of recombination between these two provincial

Table 6. Pairwise matrix of genetic differentiation $\varphi p t$ values for seven subpopulations of Puccinia striiformis $\mathrm{f}$. sp. tritici sampled from Xinjiang, Qinghai, and Gansu Provinces of northwestern China ${ }^{\mathrm{a}}$

\begin{tabular}{lccccccc}
\hline & ALT & QHE & TC & XN & XM & GH & GS \\
\hline ALT & $\ldots$ & 0.172 & 0.005 & 0.001 & 0.001 & 0.001 & 0.001 \\
QHE & 0.005 & $\ldots$ & 0.096 & 0.001 & 0.005 & 0.001 & 0.001 \\
TC & 0.023 & 0.012 & $\ldots$ & 0.001 & 0.035 & 0.003 & 0.001 \\
XN & 0.042 & 0.036 & 0.046 & $\ldots$ & 0.001 & 0.001 & 0.001 \\
XM & 0.024 & 0.021 & 0.014 & 0.032 & $\ldots$ & 0.307 & 0.001 \\
GH & 0.034 & 0.032 & 0.027 & 0.030 & 0.002 & $\ldots$ & 0.001 \\
GS & 0.055 & 0.047 & 0.041 & 0.055 & 0.070 & 0.084 & $\ldots$ \\
\hline
\end{tabular}

a ALT $=$ Aletai included, $\mathrm{QHE}=$ Qinghe included, $\mathrm{TC}=$ Tacheng, Emin, and Yumin included, $\mathrm{XN}=$ including Xining, $\mathrm{XM}=$ including Xunhua and Minhe, and GH $=$ including Guide, Jiazha, and Hualong. Lower left part = $\varphi p t$ values and upper right part $=P$ values based on 999 permutations.

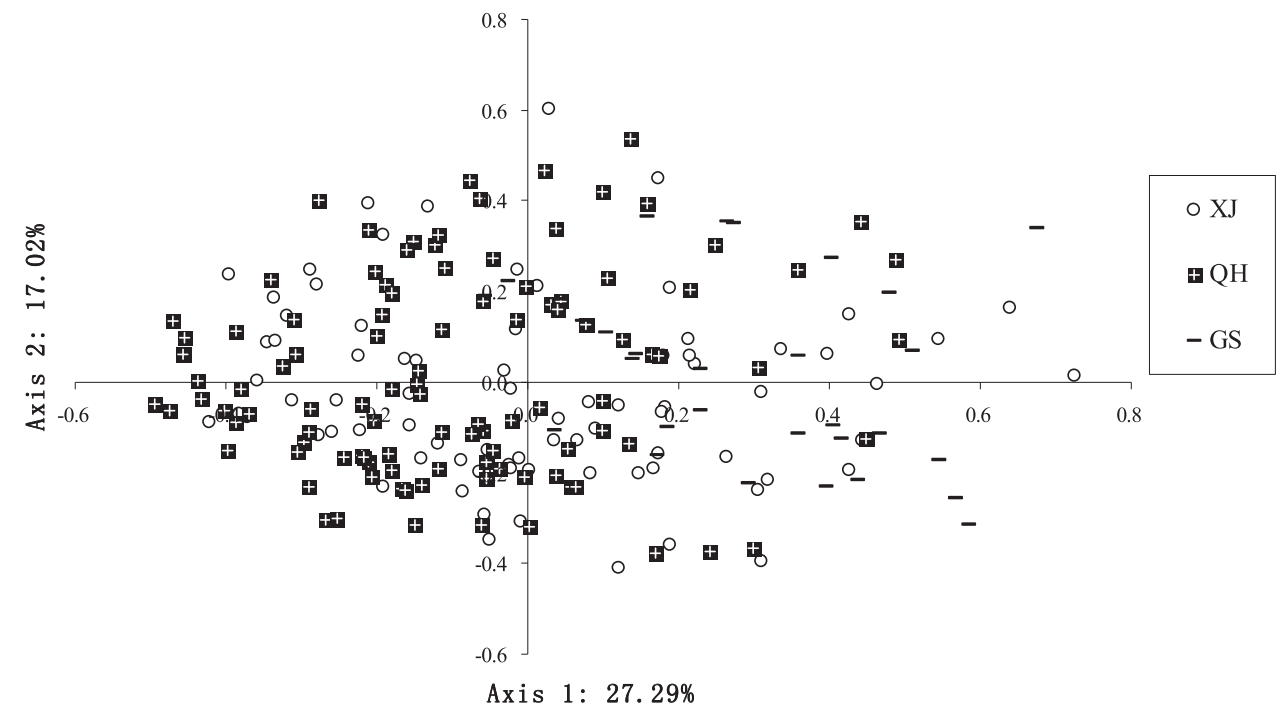

Fig. 4. Result of principal coordinates analysis (PCA) on seven subpopulations of Puccinia striiformis $\mathrm{f}$. sp. tritici showing the classification of amplified fragment length polymorphism genotypes obtained from Xinjiang (XJ), Qinghai (QH), and Gansu (GS) Provinces. Each successive axis explains proportionately less of the total variation, and axis1 and axis2 explain 27.29 and $17.02 \%$ of total variance, respectively. 
populations were also found (Liang et al. 2013). This study concluded that Ningxia can be considered to be the same population as Gansu.

The present study also indicated that genotypic diversity was much higher in the Gansu population than in the Xinjiang or Qinghai population. Moreover, the frequency of the unique genotypes in Gansu was the highest among the three populations. This may imply that Gansu population had a greater influence on Xinjiang or Qinghai population.

The PCA plots showed that the Xinjiang population was genetically closer to the Qinghai population than to the Gansu population. Furthermore, the result of AMOVA showed that the genetic differentiation between Xinjiang and Gansu populations (0.050) was much higher than that between Xinjiang and Qinghai populations (0.019) (Table 5). In terms of both genotypic diversity and genetic diversity, the order is Gansu > Xinjiang > Qinghai. In addition to the existence of shared genotypes among these three populations, it seemed that the most possible dispersal or migration direction of the $P$. striiformis f. sp. tritici populations might be from Gansu to Qinghai or to Xinjiang, but not the reverse direction. This inference is based on the theory of population genetics about relationships between two populations which states that, when genetic exchange exists, the migration direction would be likely from one with higher genetic or genotypic diversity to one with lower diversity. However, genetic and other direct evidence explaining why the genotypic and genetic diversities of Xinjiang population were higher than those of Qinghai population still need to be determined.
In the Xinjiang population, 17 races were identified from 43 isolates, demonstrating high race diversity distributed in different geographic locations. Although there remains no evidence to show that Xinjiang is one of source regions where new races of $P$. striiformis f. sp. tritici, predominating in China, could be initiated, our result showed that the sampled population in Xinjiang in this study was at least likely not from a recombined population. Possible exchange in $P$. striiformis f. sp. tritici populations between Xinjiang and neighboring countries has not been determined. A larger number of isolates is required in order to answer the question about the possible existence of recombining process in the population relating to new race initiation and race diversity.

The possible reproductive mode of $P$. striiformis $\mathrm{f}$. sp. tritici populations in China had been intensively studied by different institutes, especially for the Gansu populations. Mboup et al. (2009) suggested the existence of a sexual or parasexual cycle in P. striiformis $\mathrm{f}$. $\mathrm{sp}$. tritici populations in Tianshui county of Gansu Province, China. Duan et al. (2010) studied the P. striiformis f. sp. tritici genetic diversity in Gansu by comparing it with that of European populations using AFLP. The results demonstrated the high possibility of recombination in Gansu population. Liu et al. (2011) studied the population genetics of the pathogen among different populations in Yunnan (southwestern China) and Gansu Provinces using AFLP, and concluded that a recombination signature was detected in Gansu populations but not in Yunnan populations. Lu et al. (2011) studied spatial genetic diversity and possible interregional dispersal of P. striiformis f. sp. tritici between Qinghai and Gansu Provinces of
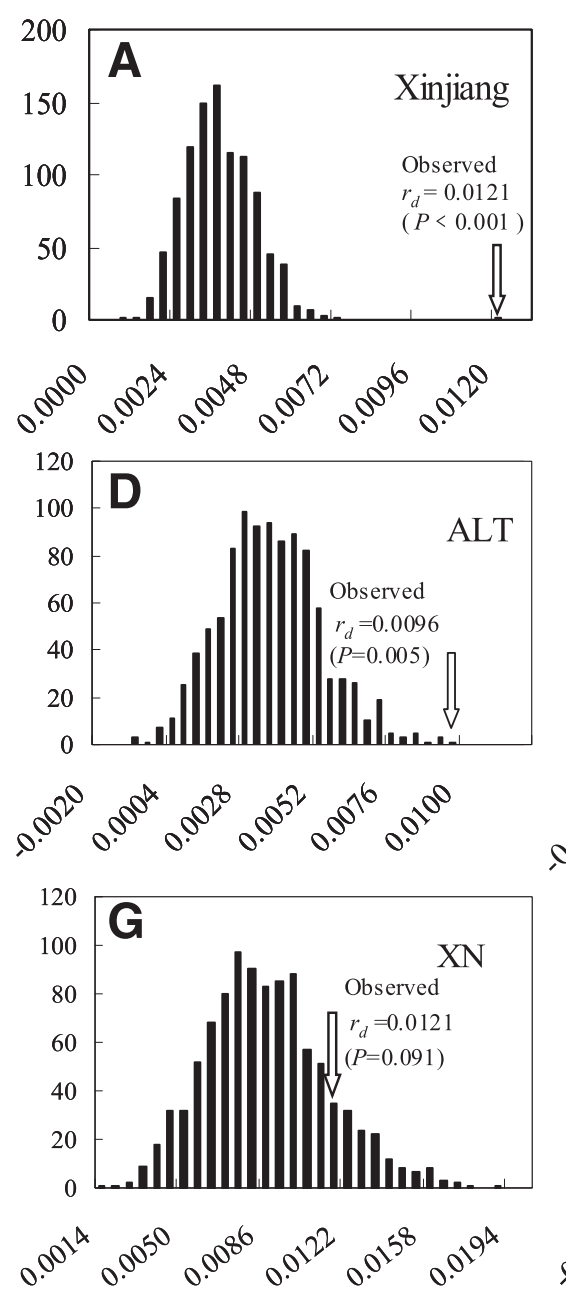
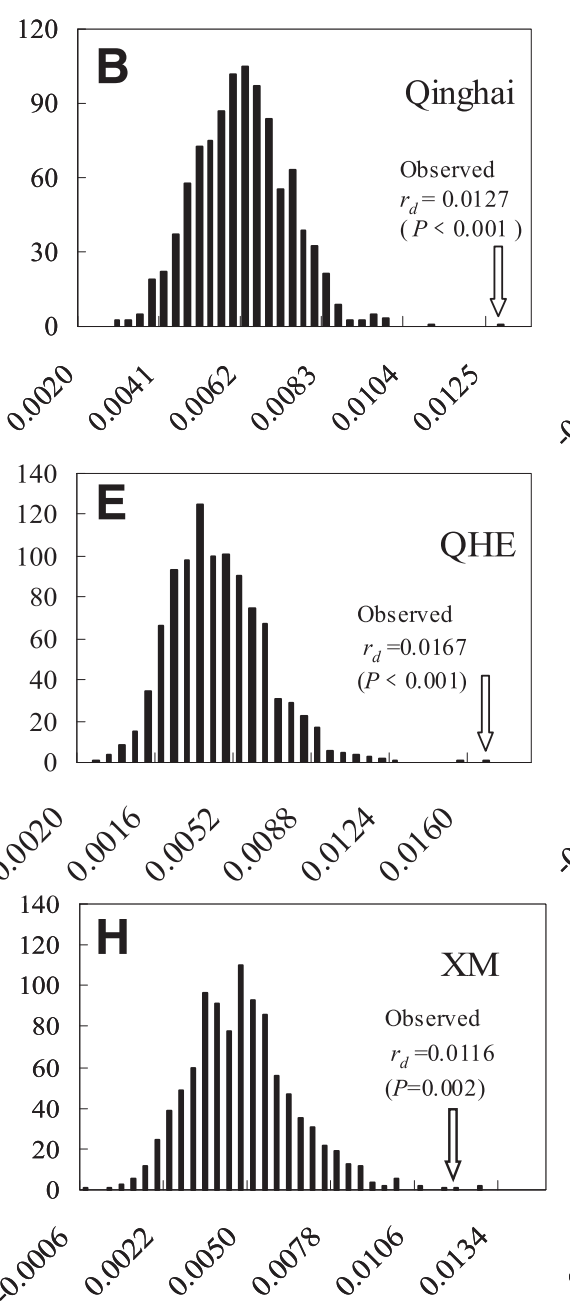
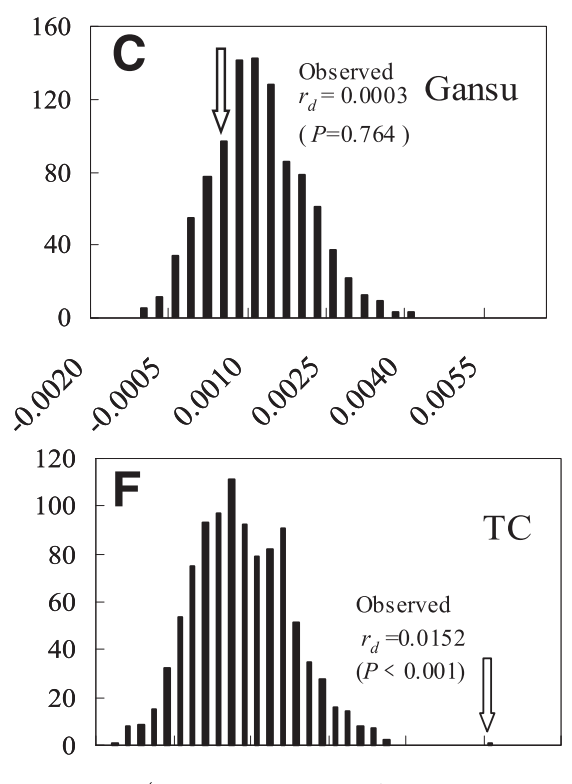

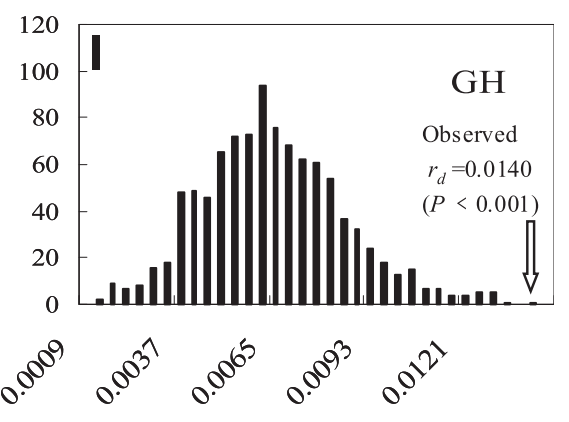

Fig. 5. Distributions of standardized association index $\left(r_{d}\right)$ from 1,000 randomized datasets and the locations of the observed $r_{d}$ values for the $\mathbf{A}$, Xinjiang; $\mathbf{B}$, Qinghai; and $\mathbf{C}$, Gansu populations and D, E, and F, three subpopulations in Xinjiang (ALT = Aletai included, QHE = Qinghe included, and TC = Tacheng, Emin, and Yumin included) and G, H, and I, three subpopulations in Qinghai (XN = including Xining, XM = including Xunhua and Minhe, and $\mathrm{GH}=$ including Guide, Jiazha, and Hualong). Amplified fragment length polymorphism genotype data were used in analysis for the three provinces. 
China using simple-sequence repeat markers, and concluded that the stripe rust inoculum in Qinghai may come from both Longnan and Linxia of Gansu Province but mainly from Longnan directly in the spring. All of these studies detected higher genetic diversity of $P$. striiformis $\mathrm{f}$. sp. tritici populations in Gansu than in other regions of China. Liang et al. (2013) studied the population genetic structures of $P$. striiformis $\mathrm{f}$. sp. tritici in Ningxia and Gansu of China by using AFLP and found the occurrence of frequent population exchanges between these two regions, and a high possibility of recombination in some of the studied subpopulations in both provinces. Jin et al. (2010) demonstrated that Berberis spp. can be alternate hosts for the wheat stripe rust pathogen. This study confirmed the conclusion about the existence of a recombination process in Gansu, and the recombination signature may also exist in some subpopulations of Qinghai. However, in Xinjiang, at least the sampled subpopulations might be from clonal populations with very small chance of recombination.

Thus far, no clear relationship between virulence phenotype and genetic genotype for the P. striiformis f. sp. tritici populations had been found (Chen et al. 1993; Keiper et al. 2006). The present study also showed no significant correlation between the AFLP similarity matrix and the virulence similarity matrix for both Xinjiang and Qinghai populations. The races of $P$. striiformis f. sp. tritici in Gansu

Table 7. Numbers of the tested isolates of Puccinia striiformis f. sp. tritici with amplified fragment length polymorphism (AFLP) and the corresponding physiologic races for the populations of Xinjiang and Qinghai, northwestern China, and the corresponding information from Gansu from Huang et al. (2014) as a comparison with Xinjiang and Qinghai

\begin{tabular}{|c|c|c|c|c|}
\hline Province, population ${ }^{a}$ & Isolates $^{\mathbf{b}}$ & Number of races & Race diversity & Race (number of isolates) ${ }^{\mathrm{c}}$ \\
\hline \multicolumn{5}{|l|}{ Xinjiang } \\
\hline ALT & 11 & 8 & 0.73 & $\begin{array}{l}\text { Su11-2(2), Su11-3(2), Su11-5(1), Su11-6(1), } \\
\text { Su11-8(1), CYR21(2), CYR23(1), CYR28(1) }\end{array}$ \\
\hline QHE & 15 & 9 & 0.60 & $\begin{array}{l}\text { HY-6(2), HY-9(2), Su11-3(1), Su11-4(1), } \\
\text { Su11-10(1), CYR17(1), CYR18(2), } \\
\text { CYR21(2), CYR25(1), other(2) }\end{array}$ \\
\hline $\mathrm{TC}$ & 15 & 8 & 0.53 & $\begin{array}{l}\text { HY-9(1), Su11-3(1), Su11-4(1),Su11-8(3), } \\
\text { Su11-10(3), Su11-11(1), Su11-13(3), } \\
\text { CYR17(2) }\end{array}$ \\
\hline $\mathrm{XY}$ & 2 & 2 & 1.00 & HY-9(1), Su11-8(1) \\
\hline Subtotal & 43 & 17 & 0.40 & \\
\hline \multicolumn{5}{|l|}{ Qinghai } \\
\hline $\mathrm{XM}$ & 17 & 12 & 0.71 & $\begin{array}{l}\text { CYR21(1), HY-7(1), HY-8(1), HY-30(1), } \\
\text { Su11-3(1), Su11-5(1), Su11-16(1), } \\
\text { Su11-18(4), Su11-30(1), Su11-33(1), } \\
\text { Su11-60(1), Zhong 4-4(1), other(2) }\end{array}$ \\
\hline GH & 8 & 5 & 0.63 & $\begin{array}{l}\text { HY-6(1), Su11-4(2), Su11-6(1), Su11-9(1), } \\
\text { CYR33(2), other(1) }\end{array}$ \\
\hline Subtotal & 25 & 17 & 0.68 & \\
\hline \multicolumn{5}{|l|}{$\mathrm{Gansu}^{\mathrm{d}}$} \\
\hline Subtotal & 320 & 30 & 0.09 & $\begin{array}{l}\text { CYR21(1), CYR25(1), CYR27(1), CYR28(1), } \\
\text { Lv13-VIII(1), CYR31(1), CYR32(63), HY-4(1), } \\
\text { HY-5(6), HY-6(1), HY-8(4), HY-9(2), } \\
\text { HY-29(1), Su11-2(3), Su11-3(7), Su11-4(54), } \\
\text { Su11-5(14), Su11-6(1), Su11-10(2), } \\
\text { Su11-12(5), Su11-13(3), Su11-35(31), } \\
\text { Su11-41(10), Su11-60(12), CYR33(61), } \\
\text { G22-9(9), Zhong4-1(2), Zhong4-3(1), } \\
\text { Zhong4-4(1), YR5-1(3), others(17) }\end{array}$ \\
\hline
\end{tabular}

a ALT = Aletai included, QHE = Qinghe included, TC = Tacheng, Emin, and Yumin included, XN = including Xining, XM = including Xunhua and Minhe, and $\mathrm{GH}=$ including Guide, Jiazha, and Hualong.

${ }^{b}$ Number of isolates analyzed for their virulence.

c The virulence/avirulence patterns used to identify races of $P$. striiformis f. sp. tritici were based on Chen et al. (2009) and Wan et al. (2004).

${ }^{d}$ The information on corresponding physiologic races of $P$. striiformis $\mathrm{f}$. sp. tritici for Gansu population was based on Huang et al. (2014) and resulted from 320 isolates of $P$. striiformis f. sp. tritici collected from different locations of Gansu Province.

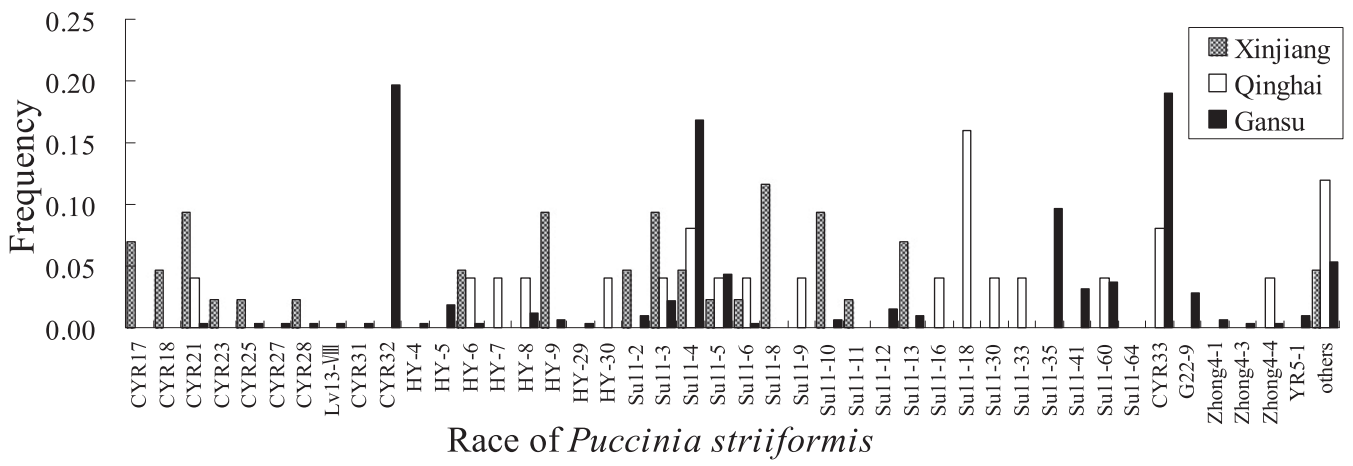

Fig. 6. Frequency of different physiologic races of Puccinia striiformis f. $\mathrm{sp}$. tritici of the selected isolates collected from Xinjiang (43 isolates) and Qinghai (25 isolates) Provinces identified in this study using the standard Chinese differential system. As a comparison with Gansu, the corresponding frequency data for $P$. striiformis $\mathrm{f}$. sp. tritici races for $\mathrm{Gansu}$ Province were from Huang et al. (2014), based on 320 isolates. 
Province have been routinely monitored every year in China. Jia et al. (2011) studied 1,966 P. striiformis f. sp. tritici samples collected in Gansu Province from 2004 to 2009, and found that the major predominant races in Gansu were CYR33 and CYR32, which belonged to the Hybrid46 and Shuiyuan 11 pathotype groups. Huang et al. (2014) identified races from 1,008 samples collected from 2010 to 2012 and showed that CYR33 and CYR32 were still the predominant race, with occurrence frequencies of 19.06, 29.88 , and $16.29 \%$ and $24.49,16.69$, and $30.57 \%$, respectively, in the three years. Furthermore, two new races that first appeared in 2010 and 2011 were determined to be virulent to the differential Guinong 22. They were named G22-9 and G22-14, respectively. From 2010 to 2012, the occurrence frequency of G22-9 had increased from 2.81 to $10.86 \%$ and the frequencies of G22-14 in 2011 and 2012 were 7.40 and $2.57 \%$, respectively. Huang et al. (2014) demonstrated that less than $10 \%$ of the tested isolates from Gansu in 2010 were virulent to Zhong $4(\mathrm{Yr}+)$, T. spelta album $(Y r 5)$, or Guinong $22(Y r+) ; 34 \%$ to Hybrid 46 (Yr4b, H46); $60 \%$ to Lovrin $13(\mathrm{Yr} 9+)$; and more than $80 \%$ to the rest of the differentials.

In Qinghai, there was a complex race structure, with a number of races named later than CYR31 and with high frequencies of Su11-18, Su11-4, and CYR33 as predominant races. Moreover, a few isolates were detected to be virulent to Zhong 4 or Guinong 22 at a frequency of $4.0 \%$. These results implied that the race dynamics of Qinghai were consistent with those of Gansu.

Nonetheless, in the tested Xinjiang population, CYR29, CYR30, CYR31, CYR32, and CYR33 had not been detected yet, and CYR28 was only detected once. Furthermore, CYR17, CYR18, CYR21, and CYR23 were all detected and CYR21 were surprisingly detected four times, with a frequency $=0.09$. These results revealed that dynamics of $P$. striiformis f. sp. tritici races in Xinjiang Province may follow those in Gansu and other interior epidemic regions of China. In this study, the longest distance between Xinjiang and Gansu sampling locations was more than $2,300 \mathrm{~km}$ and the shortest one was still over $1,600 \mathrm{~km}$. In addition to a number of mountains and the enormous desert, these geographical characteristics may cause a long-term temporal hysteresis for race dynamics and structures in Xinjiang.

Table 8. Differential cultivars and percentages of tested isolates of Puccinia striiformis with virulence to the corresponding differentials from the tested isolates in Xinjiang and Qinghai provinces of northwestern China

\begin{tabular}{llcc}
\hline & & \multicolumn{2}{c}{$\begin{array}{c}\text { Isolates with } \\
\text { virulence (\%) }\end{array}$} \\
\cline { 3 - 4 } Differential & \multicolumn{1}{c}{ Yr gene $^{\mathbf{a}}$} & Xinjiang & Qinghai \\
\hline Trigo Eureka & 6 & 58.1 & 40.0 \\
Fulhard & Unknown & 90.7 & 64.0 \\
Lutescens 128 & Unknown & 90.7 & 92.0 \\
Mentana & Unknown & 79.1 & 76.0 \\
Virgilio & Vir1,Vir2 & 25.6 & 36.0 \\
Abbondanza & Unknown & 93.0 & 100.0 \\
Early Premium & Unknown & 93.0 & 80.0 \\
Funo & A, + & 81.4 & 96.0 \\
Danish 1 & 3 & 72.1 & 56.0 \\
Jubilejina 2 & Ju1, Ju2, Ju3, Ju4 & 44.2 & 96.0 \\
Fengchan 3 & 1 & 86.1 & 72.0 \\
Lovrin 13 & $9,+$ & 0 & 36.0 \\
Kangyin 655 & 1, Ky1, Ky2 & 27.9 & 48.0 \\
Shuiyuan 11 & Su & 67.4 & 88.0 \\
Zhong 4 & Unknown & 0 & 4.0 \\
Lovrin 10 & 9 & 9.3 & 52.0 \\
Hybrid 46 & $4 b$, H46 & 14.0 & 24.0 \\
Triticum spelta album & 5 & 0 & 0 \\
Guinong 22 & Unknown & 0 & 4.0 \\
\hline
\end{tabular}

a $Y r$ genes were based on Cao (2008), Chen et al. (2009), Chen et al. (1995), McIntosh et al. (1995), Roelfs et al. (1992), Stubbs (1985), and Wan et al. (2004).

\section{Acknowledgments}

We thank J. Li (Xinjiang Plant Protection Station [XPPS]), D. Yang (Institute of Plant Protection, Xinjiang Academy of Agricultural Sciences), Q. Guo, Q. Yao, and J. Yan, (Qinghai Academy of Agricultural Sciences), H. Li (Gansu Plant Protection Station [GPPS]), and the colleagues in the following county stations for their assistance in sample collection: Aletai, Qinghe, Tacheng, Emin, Yumin, and Xinyuan under XPPS and Zhuanglang, Tianshui, Kangle, and Jishishan under GPPS and W. Leng, Y. Li, M. Yuan, T. Liu, and X. Xi (Department of Plant Pathology, China Agricultural University) and W. Gong (University of Tibet, China) for their assistance in pathogen reproduction. This work was supported by National Key Basic Research Program of China (number 2013CB127700) and National Natural Science Foundation of China (number 31401684).

\section{Literature Cited}

Agapow, P. M., and Burt, A. 2001. Indices of multilocus linkage disequilibrium Mol. Ecol. Notes 1:101-102.

Cao, S. Q. 2008. Analysis to virulent genes of CY32 and Shuil4 pathotype to Puccinia striiformis f. sp. tritici. Gansu Agric. Sci. Technol. 46:8-10.

Chen, W. Q., Wu, L. R., Liu, T. G., Xu, S. C., Jin, S. L., Peng, Y. L., and Wang, B. T. 2009. Race dynamics, diversity, and virulence evolution in Puccinia striiformis $\mathrm{f}$. $\mathrm{sp}$. tritici, the causal agent of wheat stripe rust in China from 2003 to 2007. Plant Dis. 93:1093-1101.

Chen, X. M. 2005. Epidemiology and control of stripe rust [Puccinia striiformis f. sp. tritici] on wheat. Can. J. Plant Pathol. 27:314-337.

Chen, X. M., Jones, S. S., and Line, R. F. 1995. Chromosomal location of genes for stripe rust resistance in spring wheat cultivars Compair, Fielder, Lee, and Lemhi and interactions of aneuploid wheats with races of Puccinia striiformis. Phytopathology 85:375-381.

Chen, X. M., Line, R. F., and Leung, H. 1993. Relationship between virulence variation and DNA polymorphism in Puccinia striiformis. Phytopathology 83:1489-1497.

Duan, X. Y., Tellier, A., Wan, A. M., Leconte, M., de Vallavieille-Pope, C., and Enjalbert, J. 2010. Puccinia striiformis f. sp. tritici presents high diversity and recombination in the over-summering zone of Gansu, China. Mycologia 102:44-53.

Enjalbert, J., Duan, X., Giraud, T., Vautrin, D., de Vallavieille-Pope, C., and Solignac, M. 2002. Isolation of twelve microsatellite loci, using an enrichment protocol, in the phytopathogenic fungus Puccinia striiformis f. sp. tritici. Mol. Ecol. Notes 2:563-565.

Excoffier, L., Smouse, P. E., and Quattro, J. M. 1992. Analysis of molecular variance inferred from metric distances among DNA haplotypes: Application to human mitochondrial DNA restriction data. Genetics 131:479-491.

Felsenstein, J. 1989. Phylip: Phylogeny inference package (version 3.2). Cladistics 5:164-166.

Huang, J., Jia, Q. Z., Jin, S. L., Cao, S. Q., Zhang, B., Sun, Z. Y., Luo, H. S., and Wang, X. M. 2014. Population changes of Puccinia striiformis f. sp. tritici in Gansu Province during 2010-2012. Plant Prot. 40:101-105.

Jia, Q. Z., Jin, S. L., Cao, S. Q., Lou, H. S., Jin, M. A., Zhang, B., and Huang, J. 2011. Physiologic specialization of wheat stripe rust in Gansu Province during 2004-2009. China Agric. Sci. Bull. 27:85-90.

Jin, Y., Szabo, L. J., and Carson, M. 2010. Century-old mystery of Puccinia striiformis life history solved with the identification of Berberis spp. as an alternate host. Phytopathology 100:432-435.

Justesen, A. F., Ridout, C. J., and Hovmøller, M. S. 2002. The recent history of Puccinia striiformis f. sp. tritici in Denmark as revealed by disease incidence and AFLP markers. Plant Pathol. 51:13-23.

Keiper, F. J., Haque, M. S., Hayden, M. J., and Park, R. F. 2006. Genetic diversity in Australian populations of Puccinia graminis f. sp. avenae. Phytopathology 96:96-104.

Li, J., Zeng, J., Jang, Y. Y., and Li, H. 2010. Characteristics of incidence and epidemics of Puccinia striiformis f. sp. tritici in Xinjiang Province of China. China Plant Prot. 30:16-19.

Li, Z. Q., Wang, M. N., Jia, M. G., Lu, H. L., Shang, H. S., Kang, Z. S., Yang, S. F., Sun, S. M., and Shi, Y. C. 1997. Study on the epidemiology and control strategy of wheat stripe rust in Longnan of Gansu. Acta Univ. Agric. BorealiOccidentalia 25:1-5.

Li, Z. Q., and Zeng, S. M. 2002. Wheat Rusts in China. China Agricultural Press, Beijing.

Liang, J.-M., Wan, Q., Luo, Y., and Ma, Z.-H. 2013. Population genetic structures of Puccinia striiformis in Ningxia and Gansu of China. Plant Dis. 97:501-509.

Liu, X.-F., Huang, C., Sun, Z. Y., Liang, J.-M., Luo, Y., and Ma, Z.-H. 2011. Analysis of population structure of Puccinia striiformis in Yunnan Province of China by using AFLP. Eur. J. Plant Pathol. 129:43-55.

Lu, N. H., Wang, J. F., Chen, X. M., Zhan, G. M., Chen, C. Q., Huang, L. L., and Kang, Z. S. 2011. Spatial genetic diversity and interregional spread of Puccinia striiformis f. sp. tritici in Northwest China. Eur. J. Plant Pathol. 131:685-693.

Mboup, M., Leconte, M., Gautier, A., Wan, A. M., Chen, W., de Vallavieille-Pope, C., and Enjalbert, J. 2009. Evidence of genetic recombination in wheat yellow rust populations of a Chinese oversummering area. Fungal Genet. Biol. 46 299-307. 
McIntosh, R. A., Wellings, C. R., and Park, R. F. 1995. Wheat Rusts: An Atlas of Resistance Genes. Commonwealth Scientific and Industrial Research Organization, Australia, and Kluwer Academic Publishers, Dordrecht, The Netherlands.

Page, R. D. M. 1996. TreeView: An application to display phylogenetic trees on personal computers. Comput. Appl. Biosci. 12:357-358.

Peakall, R., and Smouse, P. E. 2006. GENALEX 6: Genetic analysis in Excel. Population genetic software for teaching and research. Mol. Ecol. Notes 6: 288-295.

Roelfs, A. P., Singh, R. P., and Saari, E. E. 1992. Rust Diseases of Wheat: Concepts and Methods of Disease Management. CIMMYT, D. F., Mexico.

Rohlf, F. J. 2000. NTSYS pc. Numerical Taxonomy and Multivariate Analysis System, version 2.1. Exeter Publications, New York.

Smith, S. M., Smith, N. H., O'Rourke, M., and Spratt, B. G. 1993. How clonal are bacteria? Proc. Natl. Acad. Sci. USA 90:4384-4388.

Stubbs, R. W. 1985. Stripe rust. Pages 61-101 in: The Cereal Rusts, Vol. II. A. P. Roelfs and W. R. Bushnell, eds. Academic Press, New York.

Vos, P., Hogers, R., Bleeker, M., Reijans, M., Lee, T., Hornes, M., Friters, A., Pot, J., Paleman, J., and Kuiper, M. 1995. AFLP: A new technique for DNA fingerprinting. Nucleic Acids Res. 23:4407-4414.
Wan, A., Zhao, Z., Chen, X., He, Z., Jin, S., Jia, Q., Yao, G., Yang, J., Wang, B. Li, G., Bi, Y., and Yuan, Z. 2004. Wheat stripe rust epidemic and virulence of Puccinia striiformis f. sp. tritici in China in 2002. Plant Dis. 88:896-904.

Wan, A. M., Chen, X. M., and He, Z. H. 2007. Wheat stripe rust in China. Aust. J. Agric. Res. 58:605-619.

Wu, L. R. 1991. Monitoring data of P. striiformis races of China in 1989, 1990 Plant Prot. 17:22-23.

Yeh, F. C., Yang, R. C., Boyle, T. B. J., Ye, Z. H., and Mao, J. X. 1997 POPGENE, the User-Friendly Shareware for Population Genetic Analysis. Molecular Biology and Biotechnology Centre, University of Alberta, Canada. Zeng, S. M., and Luo, Y. 2006. Long-distance spread and interregional epidemics of wheat stripe rust in China. Plant Dis. 90:980-988.

Zhang, J. 2008. Oversummering areas, occurrence rules and natural conditions influence on wheat stripe rust in Qinghai Province of China. Qinghai Agric Technol. Ext. 23:44-46.

Zhao, J., Wang, L., Wang, Z. Y., Chen, X. M., Zhang, H. C., Yao, J. N., Zhan, G. M., Chen, W., Huang, L. L., and Kang, Z. S. 2013. Identification of eighteen Berberis species as alternate hosts of Puccinia striiformis f. sp. tritici and virulence variation in the pathogen isolates from natural infection of barberry plants in China. Phytopathology 103:927-934. 